Tohoku J. exp. Med., 1973, 110, 235-245

\title{
The Effect of Autonomic Drugs on the Canine Electroureterogram
}

\author{
Seigi Tsuchida, Hiroatsu Sugawara, Satoshi Matsumura, \\ Yoshitaka Shibuya and Akinori Nishryama* \\ Department of Urology, and Department of Applied Physiology, * \\ Tohoku University School of Medicine, Sendai
}

Tsuchida, S., Sugawara, H., Matsumura, S., Shibuya, Y. and Nishiyama, A. The Effect of Autonomic Drugs on the Canine Electronteterogram. Tohoku J. exp. Med., 1973, 110 (3), 235-245—Excluding the influence of changing urine flow by ligating the renal vein, canine electroureterographic studies were conducted to evaluate the effects of autonomic drugs upon the ureteral function. Intra-aortic administration of epinephrine, norepinephrine, phenylephrine, some amounts of acetylcholine, and dimethylphenylpiperazinium (DMPP) accelerated ureteral peristalsis. In the preadministration of phentolamine, epinephrine prolonged discharge intervals, and the response was suggestive of $\beta$ effect. Phentolamine, propranolol, neostigmine, atropine, hexamethonium and tetrodotoxin caused no changes in electroureterograms. - ureteral peristalsis; electroureterogram; autonomic drug

The agents, which are pharmacologically active on smooth muscle cells of the ureter, cause contraction or relaxation and change their spike generation though the exact mechanism is not clearly understood. Theoretically, this course should govern an equivalent trend in the outcomes in both in vitro and in vivo experiments, but the actual findings have been conflicting with each other when many drugs are concerned.

The incongruity in the results may be due to the difference between experimental conditions in vitro and in vivo. As far as in vitro studies are concerned, experimental conditions can be controlled consistently and the results are expected to be relatively congruous, but it is extremely difficult to control experimental conditions for in vivo studies; besides the inevitable limitation in techniques for recording ureteral activities in situ, there are many factors which affect the ureteral activity, such as temperature, blood flow, ph of urine, and the amount of urine excreted.

Among these factors, the change in the amount of urine flow seems the most difficult problem in pharmacological effects on ureteral peristalsis. As has been noted in our previous report (Tsuchida 1969), ureteral peristalsis is markedly affected by the change in the amount of urine flow. Therefore, the drugs which affect renal function change urine flow, and as the result of change in urine flow,

Received for publication, April 8, 1972.

Director: Prof. S. Shishito.

* Director: Prof. T. Suzuki. 
ureteral activity might be affected. So, in the event of changed ureteral activity, it is usually difficult to evaluate the effect of autonomic drugs independently of the effect of the changed urine flow. In other words, the effects of pharmacologically active agents on ureteral activity cannot be identified without eliminating the influence of urine flow.

In our previous electroureterographic study performed in an attempt to settle this problem (Tsuchida 1971), we reported that the ligation of the renal vein blocked urine secretion and that under these conditions stable peristaltic responses near the normal were obtained. This arrangement has been considered to be adequate in monitoring ureteral peristalsis in relation to the effects of drugs.

The same technique of urine flow block was utilized in the present study to evaluate the effects of various autonomic drugs on the ureteral activity in dogs.

\section{Materials and Methods}

The animals used in the experiments were 75 adult dogs weighing 9 to $15 \mathrm{~kg}$. The dogs were anesthetized with sodium pentobarbital, $20 \mathrm{mg} / \mathrm{kg}$ i.v. and prepared for experimentation. When tetrodotoxin (TTX) was applied, an artificial respirator was used by intra-tracheal intubation as it causes respiratory paralysis. Administration of two or more drugs in one dog was performed at least one hour apart.

The experiments were earried out in the same manner as shown in our previous report (Tsuchida 1971). Action potentials on electroureterograms were measured in 3 respects: interval, amplitude, and travel rate of the action potential. Measurements were made in the manner reported by Tsuchida and Kimura (1964), 0-1 minute before and after the injection of a drug. During the experiments, the urinary bladder was carefully prevented from filling with urine. The left femoral artery was cannulatd with a polyethylene tube which was led to a manometric transducer for measurements of arterial blood pressure. Using the method of Boyarsky et al. (1967) which provides an accessible route for the intra-arterial application of drugs, a polyethylene tube was inserted from the right femoral artery into the aorta $45 \mathrm{~cm}$ above the branching point of the renal artery.

Drugs utilized in this study were dissolved in $10 \mathrm{ml}$ of physiological saline and given in a concentration per kilogram body-weight and infused in about 10 seconds. The drugs used were, as adrenergic agents: epinephrine hydrochloride, norepinephrine hydrochloride, phenylephrine hydrochloride, and isoproterenol hydrochloride; as adrenergic blocking agents: phentolamine mesylate (Regitine) and propranolol hydrochloride (Inderal); as cholinergic agents: neostigmine methylsulfate and acetylcholine chloride (Ovisot); as a cholinergic blocking agent; atropine sulfate; as a ganglion stimulant: 1,1-dimethyl-4phenylpiperazinium iodide (DMPP); and as a ganglion blocking agent; hexamethonium bromide $\left(\mathrm{C}_{1}\right)$, and as a blocker of nerve conduction: tetrodotoxin (TTX).

\section{Results}

\section{Adrenergic agents}

Tabulated in Table 1 are the results of electroureterogram and blood pressure before and after application of epinephrine $(10 \mu \mathrm{g} / \mathrm{kg})$, norepinephrine $(10 \mu \mathrm{g} / \mathrm{kg})$, phenylephrine $(10 \mu \mathrm{g} / \mathrm{kg})$, isoproterenol $(1 \mu \mathrm{g} / \mathrm{kg})$, phentolamine $(100 \mu \mathrm{g} / \mathrm{kg})$, and propranolol $(100 \mu \mathrm{g} / \mathrm{kg})$. The table also includes the results obtained in the administration of epinephrine $(10 \mu \mathrm{g} / \mathrm{kg}) \quad 30-60$ seconds after the injection of phentolamine $(100 \mu \mathrm{g} / \mathrm{kg})$. As seen in Table 1 and also in Figs. 1-3, epinephrine, 
Table 1

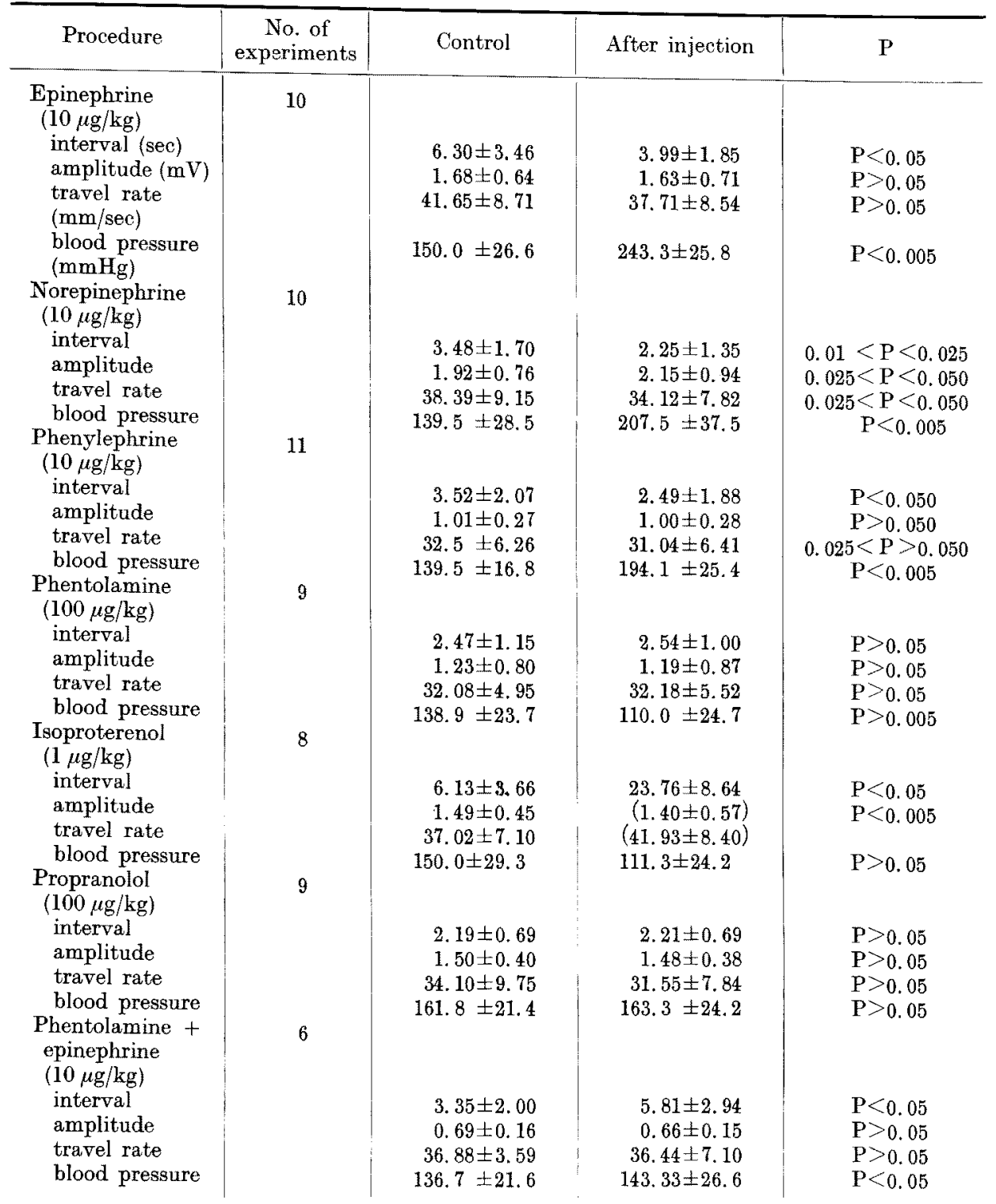

Observed values were converted into logarithms, then F-test were calculated.

The distribution of our observed values of 118 controls did not show a normal curve. After conversion into logarithms, however, the distribution seemed to be a normal curve.

norepinephrine and phenylephrine showed the effect on the electroureterograms of diminishing intervals of the action potential discharge $(\mathrm{P}<0.05)$, with the additional manifestations of the enlarged amplitude in norepinephrine and a slight prolongation in travel rates in epinephrine, though the latter was not tabulated statistically. Of 8 cases treated with isoproterenol, in 3 cases the action potential 


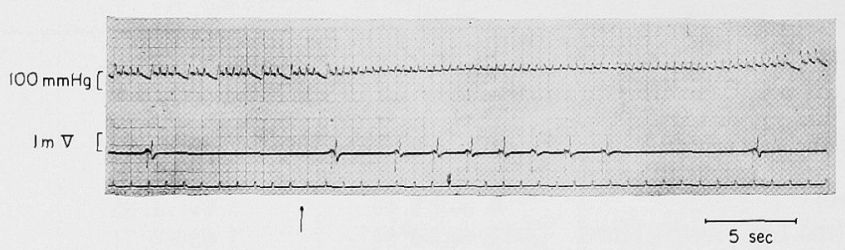

Fig. 1. Epinephrine: Effect shown in blood pressure (top) and electroureterogram (bottom).

Injection of $10 \mu \mathrm{g} / \mathrm{kg}$ epinephrine induced increase in blood pressure level, reduction in discharge interval and augmentation in amplitude of the action potential.

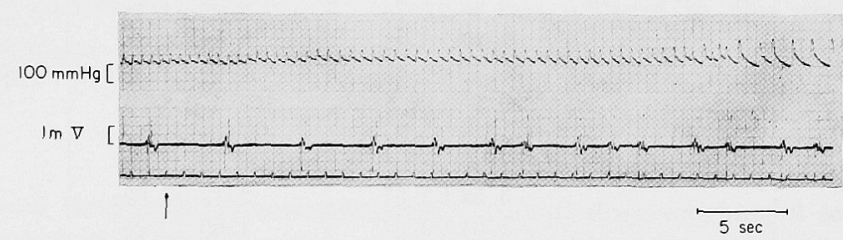

Fig. 2. Norepinephrine: Effect shown in blood pressure and electroureterogram. Injection of $10 \mu \mathrm{g} / \mathrm{kg}$ norepinephrine increased blood pressure level, reduced discharge interval and augmented amplitude of the action potential.

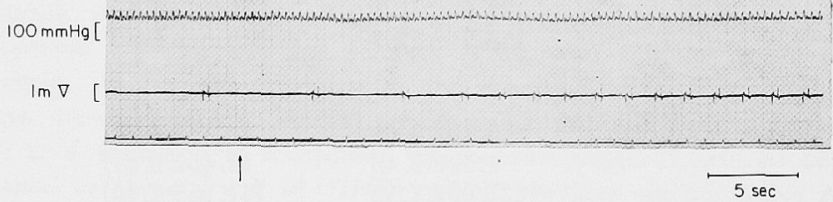

Fig. 3. Phenylephrine: Effect shown in blood pressure and electroreterogram. Injection of $10 \mu \mathrm{g} / \mathrm{kg}$ phenylephrine increased blood pressure level and reduced time interval of the action potential discharge.

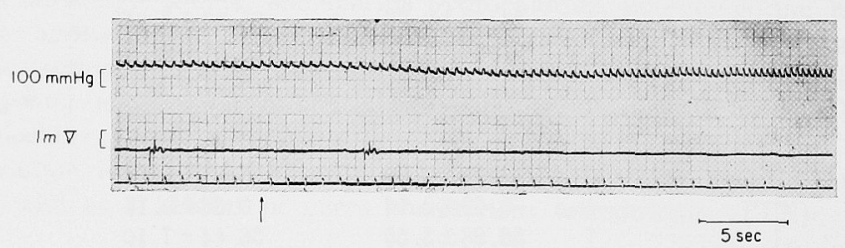

Fig. 4. Isoproterenol: Effect shown in blood pressure and electroureterogram. Injection of $1 \mu \mathrm{g} / \mathrm{kg}$ of isoproterenol was associated with a fall in blood pressure and loss of action potential.

discharge stopped for $60-150$ seconds, and in the other 5 cases a prominent prolongation in discharge interval was observed (Fig. 4). Phentolamine and propranolol showed no clear effect on ureteral activity. The epinephrine injection following the pre-administration of phentolamine had the immediate effect of a transient prolongation of a spike interval at $\mathrm{P}<0.005$ and a transient fall in blood pressure for 5-10 seconds, though the latter was not quantitated statistically (Fig. 5). 


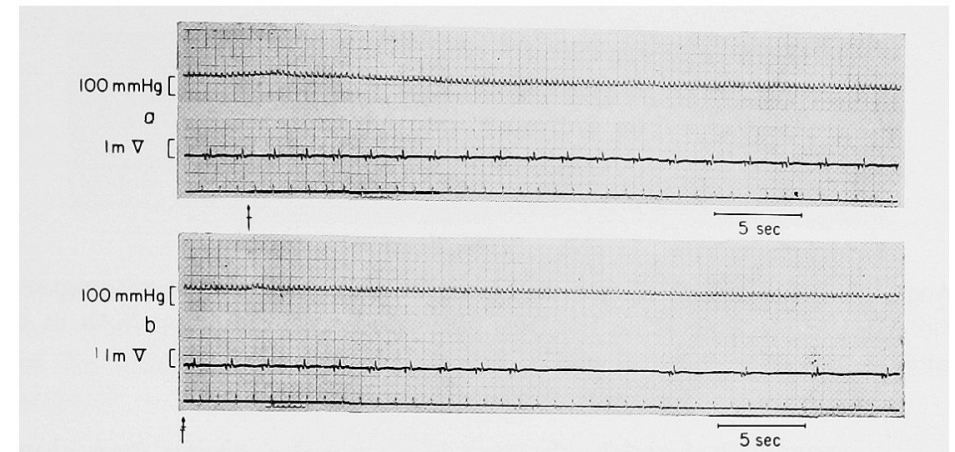

Fig. 5. Phentolamine+epinephrine: Effect shown in blood pressure and electroureterogram.

a: Injection of $100 \mu \mathrm{g} / \mathrm{kg}$ phentolamine $(\hat{\uparrow})$ produced a fall in blood pressure but no change in the discharge interval of the action potential.

b: Administration of $1 \mu \mathrm{g} / \mathrm{kg}$ epinephrine (f) 30 seconds later was associated with increase in blood pressure and prolongation of the discharge interval of the action potential.

\section{Cholinergic drugs}

The effects of the administration of neostigmine $(10 \mu \mathrm{g} / \mathrm{kg})$, acetylcholine $(50 \mu \mathrm{g} / \mathrm{kg})$, and atropine $(30 \mu \mathrm{g} / \mathrm{kg})$ with changes in ureteral activity and blood pressure were tabulated in Table 2. The acetylcholine injection was associated with an evident fall in blood pressure $(\mathrm{P}<0.05)$ and the shortening of the interval to 10-15 seconds after injection $(\mathrm{P}<0.05)$ (Fig. 6). Neostigmine and atropine showed no distinct sign of effect on the ureteral activity.

3. Ganglion stimulant and ganglion blocker

The effects of a ganglion stimulant, DMPP $(30 \mu \mathrm{g} / \mathrm{kg})$, and a ganglion blocker,

TABLE 2

\begin{tabular}{|c|c|c|c|c|}
\hline Procedure & $\begin{array}{c}\text { No. of } \\
\text { experiments }\end{array}$ & Control & After injection & $\mathrm{P}$ \\
\hline $\begin{array}{l}\text { Neostigmine } \\
(10 \mu \mathrm{g} / \mathrm{kg}) \\
\text { interval } \\
\text { amplitude } \\
\text { travel rate } \\
\text { blood pressure } \\
\text { Acetylcholine } \\
(50 \mu \mathrm{g} / \mathrm{kg}) \\
\text { interval } \\
\text { amplitude } \\
\text { travel rate } \\
\text { blood pressure } \\
\text { Atropine } \\
\text { (30 } \mu \mathrm{g} / \mathrm{kg}) \\
\text { interval } \\
\text { amplitude } \\
\text { travel rate } \\
\text { blood pressure }\end{array}$ & 18 & $\begin{array}{r}4.48 \pm 3.79 \\
1.09 \pm 0.59 \\
44.47 \pm 2.72 \\
124.8 \pm 11.6 \\
\\
4.27 \pm 3.00 \\
1.60 \pm 0.52 \\
44.15 \pm 4.92 \\
150.0 \pm 17.0\end{array}$ & $\begin{array}{r}4.58 \pm 3.98 \\
1.08 \pm 0.53 \\
43.59 \pm 7.45 \\
127.6 \pm 19.6 \\
\\
2.97 \pm 2.29 \\
1.56 \pm 0.49 \\
42.52 \pm 4.11 \\
90.0 \pm 35.9\end{array}$ & $\begin{aligned} 0.025 & <\mathrm{P}<0.05 \\
\mathrm{P} & >0.05 \\
\mathrm{P} & >0.05 \\
\mathrm{P} & <0.005\end{aligned}$ \\
\hline
\end{tabular}




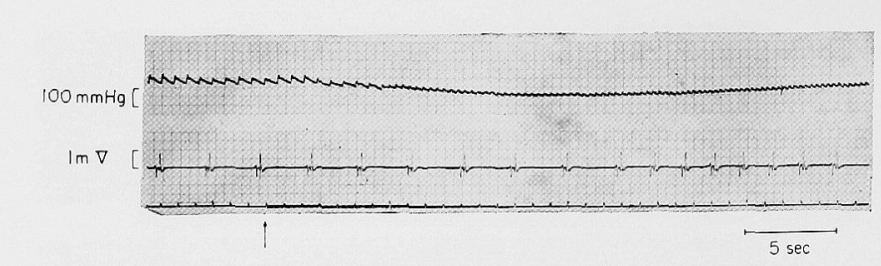

Fig. 6. Acetylcholine: Effect shown in blood pressure and electroureterogram. Injection of $100 \mu \mathrm{g} / \mathrm{kg}$ acetylcholine was associated with reduction both in blood pressure and in the spike interval of the action potential discharge.

hexamethonium $(100 \mu \mathrm{g} / \mathrm{kg})$, with changes in ureteral activity and blood pressure are tabulated in Table 3. The administration of DMPP tended to decrease the interval of the action potential discharge. This became apparent 10-20 seconds after the drug injection and continued for 30-90 seconds $(P<0.05)$. This tendency was different from the cases of epinephrine and norepinephrine in which the reduction of the interval was apparent immediately after injection. The hexamethonium induced a falling tendency in the blood pressure but had no significant effect on the electroureterogram.

Table 3

\begin{tabular}{|c|c|c|c|c|}
\hline Procedure & $\begin{array}{c}\text { No. of } \\
\text { experiments }\end{array}$ & Control & After injection & $\mathrm{P}$ \\
\hline $\begin{array}{l}\text { DMPP }(30 \mu \mathrm{g} / \mathrm{kg}) \\
\text { interval } \\
\text { amplitude } \\
\text { travel rate } \\
\text { blood pressure } \\
\text { Hexamethonium } \\
(100 \mu \mathrm{g} / \mathrm{kg}) \\
\text { interval } \\
\text { amplitude } \\
\text { travel rate } \\
\text { blood pressure }\end{array}$ & 11 & $\begin{array}{r}4.44 \pm 1.37 \\
1.32 \pm 0.52 \\
35.92 \pm 8.04 \\
115.7 \pm 11.3 \\
\\
4.00 \pm 1.19 \\
1.29 \pm 0.58 \\
27.48 \pm 5.75 \\
150.5 \pm 12.3\end{array}$ & $\begin{array}{r}3.47 \pm 1.45 \\
1.39 \pm 0.51 \\
35.39 \pm 8.91 \\
160.7 \pm 76.6 \\
\\
4.19 \pm 1.32 \\
1.26 \pm 0.60 \\
29.20 \pm 8.97 \\
132.6 \pm 17.1\end{array}$ & $\begin{aligned} \mathrm{P} & >0.05 \\
0.025 & <\mathrm{P}<0.05 \\
\mathrm{P} & >0.05 \\
\mathrm{P} & >0.05\end{aligned}$ \\
\hline
\end{tabular}

\section{Effect of $T T X$}

The influence on ureteral activity of TTX which blocks nerve conduction (Kao 1966) was studied in electroureterograms. Electrical stimulation (1 msec, $8 \mathrm{~V}, 20 \mathrm{cps}$ and for $5 \mathrm{sec}$ ) of the cervical vagal nerve following the injection of 5 $\mu \mathrm{g} / \mathrm{kg}$ of TTX was associated with a slight fall in systemic blood pressure and a slight decrease in heart rate, with evidence of insufficient blocking of nerve conduction. When the dose of TTX was increased to $10 \mu \mathrm{g} / \mathrm{kg}$, vagal stimulation had no effect on either blood pressure or heart rate indicating the complete block of nerve conduction. Therefore, $10 \mu \mathrm{g} / \mathrm{kg}$ dose of TTX was used in order to observe its effect on ureteral peristalsis. As shown in Fig. 7, the activity of the electroureterogram was not changed by the application of $10 \mu \mathrm{g} / \mathrm{kg} \mathrm{TTX}$, though the number of cases was too small to be analyzed statistically. 


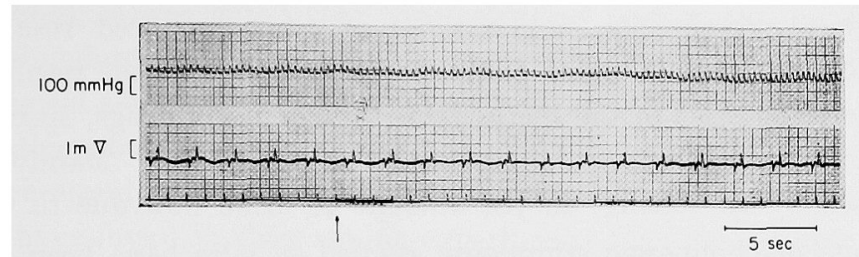

Fig. 7. Effect of TTX: Effect shown in blood pressure and electroureterogram. Injection of $10 \mu \mathrm{g} / \mathrm{kg}$ of TTX $(\uparrow)$ produced no change in discharge interval or amplitude of the action potential. Artificial ventilation was performed with intra-tracheal intubation.

\section{Discussion}

The effects of autonomic drugs on the ureteral activity have been reported in various experiments with excised human, swine, and canine ureters by Lucas (1908), Roth (1917), Satani (1919), Borgstedt et al. (1962), Deane and Garry (1966), Deane (1967), Malin et al. (1968), and Kuwabara and Rikimaru (1969). In these studies by the isometric constriction method, doses of epinephrine and norepinephrine caused increased ureteral contraction frequencies. On the other hand, no effect of phentolamine on ureteral peristalsis appeared in the investigations by Deane and Garry (1966), and Kuwabara and Rikimaru (1969). The suppression of the ureteral function by adrenergic $\beta$-receptor stimulants was reported by Malin et al. (1968), and Deane (1967). The effect of $\beta$-receptor blocking agent on ureteral peristalsis was stated in the negative by Kuwabara and Rikimaru (1969), where the concentration of propranolol was $10^{-5} \mathrm{~g} / \mathrm{ml}$.

In contrast to these in vitro experiments, in vivo studies have shown considerably conflicting results, though experimental methods were similar. The effects of epinephrine and norepinephrine both promoting ureteral contraction movement were affirmed by urometric study (Boyarsky et al. 1967; Kaplan et al. 1968) and by the intraureteral tension recording technique (Kiil and Kjekshus 1966). This effect of the agents on ureteral peristalsis, however, was denied with no affirmative sign on hydrophrograms (Lapides 1948), and on electroureterograms (Butcher et al. 1957) and also on urometrograms (Kiil 1957). Similar situations were often observed in the experiments of the application of phentolamine and isoproterenol with incongruous results, even when the drugs used were the same in brand, and in particular when the methods for analysis of the effects were different, e.g. Kiil (1957), and Kiil and Kjekshus (1966). Although the antagonistic action of $\alpha$ blockers to $\alpha$-stimulants was shown by some investigators, including Kaplan et al. (1968), no plausible elucidation has been given.

From our electroureterographic observations, it was apparent that phenylephrine, norepinephrine and epinephrine had the effect of reducing the interval of the action potential, evidently accelerating ureteral peristalsis. Also it was evident that, when combined with preadministration of phentolamine, this effect was blocked even causing a tendency to prolong the spike interval, suggesting that the $\alpha$-effect had been suppressed, giving way to the $\beta$-effect of epinephrine. 
Our in vivo experiments, unlike those in vitro, produced results which are not always compatible with other authors. Discrepancy in the results may partly be due to the differences in the methods for in situ use of drugs, species of animals used, and/or individual ureteral sensitivities of the drugs. Mainly, however, it may be caused by the change in the amount of urine flow due to the drug.

The effects of cholinergic stimulants studied in vitro have been reported with incongruous results by various workers. The effect of neastigmine affirmed by O'Conor (1939) to promote ureteral peristalsis was challenged by Chen et al. (1957), and Kuwabara and Rikimaru (1969). Also the effect of acetylcholine to increase peristaltic frequencies, confirmed by Gruber (1928) and Deane (1967), was denied by Chen et al. (1957) and Borgstedt et al. (1962). Shiratori et al. (1957) reported that in the in vivo study of neostigmine on electroureterograms, the acceleration of the ureteral activity was indiscernible with a small dose of this drug, but became evident with the increase in dose. In other experiments no effect of neostigmine was observed (Lapides 1948). Acetylcholine examined in vitro tended to promote ureteral activity in the swine ureter in studies of Gruber (1928) and Dean (1967), but had no response in the canine ureter (Chen et al. 1957). This drug, in vivo, accelerated canine ureteral contraction frequencies in the studies of Sleator and Butcher (1955) using electroureterograms and of Kiil and Kjekshus (1966) using the intraluminal tension recording technique. In our experiments, neostigmine had no effect but acetylcholine apparently accelerated ureteral activity. As for the effect of atropine on ureteral activity, suppression was noted by Satani (1919), and a tendency toward acceleration in small doses and suppression in large doses was stated by Macht (1916), while no effect was confirmed in the experiments of Chen et al. (1957), or Kuwabara and Rikimaru (1969). In experiments in vivo, we have confirmed no effect of atropine on ureteral activity in agreement with Lapides (1948) and Kill (1957). As stated above, the effects of cholinergic drugs on the ureteral function are inconsistent by various workers both in vitro and in vivo. As the result of a histochemical experiment for staining cholinesterase in the ureter, Kuwabara and Rikimaru (1969) stated that no positive reaction of specific cholinesterase activity indicated the possible absence of cholinergic nervous tissue in the ureteral musculature. From this result, it is presumed that the ureteral sensitivity to choline is extremely delicate in vivo.

No direct effect of DMPP on ureteral activity was noted by Kuwabara and Rikimaru (1969) in their in vitro experiments with the excised canine ureter, but in our experiments this ganglion stimulant accelerated ureteral peristalsis $(\mathrm{P}<$ 0.05). No distinct effect of hexamethonium on the ureteral activity has been found in our experience, in agreement with the common view of most authors.

The control of the ureteral activity of the autonomic nervous system has been argued variously by many authors. Engelmann (1869), Dogiel (1878) and Hryntschak (1925) discovered anatomically the existence of nerve cells in the ureter. However, opinions are divergent on the conditions of distribution and behavior of the peripheral nerve plexus. In the electron-microscopic observations 
of Notley (1968), it was noted that the ureter had neither ganglia nor plexus but showed an abundant distribution of sympathetic nerve fibers in the blood vessels. The physiological significance of nervous control over the ureter has been analyzed by many authors but with inconsistent interpretations. The influence of nervous control over ureteral peristalsis was positively supported by Torbey and Leadbetter (1963), who have found in their canine experiments that the bladder and the distal ureter are subject to the control of the hypogastric and pelvic nerves, which exerts influence over the ureteral peristalsis in the region proximal to the bladder.

The control of the autonomic nervous system over the ureteral function has been suggested in a series of experiments performed by Boyarsky et al. $(1966,1967$, 1968), and Boyarsky and Labay (1967), in which electrical stimulation at the renal hilum, under a state of extremely reduced urine flow, was reported to cause changes in ureteral peristalsis. They also measured the catecholamine content in the ureter by the fluorescence spectrophotometry method and noted that the ureter contained as much catecholamine as the urinary bladder, and this amount was reduced by reserpinization.

In contrast to these opinions in favor of the nervous control over ureteral activity, some negative concepts have been expressed. Hasegawa (1961) studied ureteral activities in dogs by electroureterography under conditions of completely blocked nerve supply, and reported little effect on peristaltic activities. Kiil and Kjekshus (1966) noted no influence of pelvic nerve stimulation on ureteral peristalsis when the bladder was empty and the urine flow was small. They have stated in conclusion that stimulation of renal nerves vitally affects renal blood flow and glomerular filtration, with the resultant changes in urine flow possibly producing alterations in ureteral peristalsis. We reported that normal ureteral peristalsis was observed in patients with spinal nerve injuries (Tsuchida et al. 1968). Furthermore, an autotransplantation of the canine kidney was associated with little alteration in ureteral peristalsis (Tsuchida 1970). All these experimental results seem to support indirectly no effect of the external nervous supply upon ureteral peristaltic activity.

In our present experiments, the effect of several autonomic blocking agents on ureteral peristalsis were studied. Tetrodotoxin of $10 \mu \mathrm{g} / \mathrm{kg}$, which was enough to block nerve conduction, had no effect on ureteral peristalsis. Neostigmine, as opposed to acetylcholine, showed no consistent effect on acceleration of peristaltic movement. On the other hand, atropine had no influence on electroureterograms. Furthermore, phentolamine and propranolol also caused no change in peristaltic movement. These results that autonomic blocking agents have no effect on electroureterograms show that there would be scarcely any autonomic innervation on the ureter smooth muscle.

Conflicting with this concept of little nervous control over the ureter was the effect of the ganglion stimulant in our experiments, in that DMPP accelerated spike discharge inconsistently with the results of the in vitro experiments of Kuwabara and Rikimaru (1969). Our in vivo experiments might have stimulated 
the ganglia at the renal hilum, eventually producing changes in ureteral peristalsis. However, in another possible interpretation, DMPP might have stimulated the adrenal medulla and the other postganglionic adrenergic neuron causing catecholamine secretion. In fact, the blood pressure was increased by the injection of DMPP. On the other hand, in the experiments of Kiil and Kjekshus (1966) concerning the serotonin effect on the ureteral function, it was suggested that the serotonin-induced acceleration of intestinal peristalsis might encourage the activity of ureteral peristalsis. This suggestion of the mechanical influence of accelerated intestinal peristalsis upon ureteral activity is plausible because in our experimental dogs the tendency to urinate increased following DMPP administration. Various problems, however, still remain to be settled before a final identification of the effect of DMPP upon ureteral peristalsis can be made.

\section{Acknowledgment}

Grateful acknowledgments are due to Prof. S. Shishito and Prof. T. Suzuki for their guidance and review of the manuscript.

\section{References}

1) Borgstedt, H.H., Benjamin, J.A. \& Emmel, V.M. (1962) The role of histamine in ureteral function. $J$. Pharmacol. exp. Ther., 136, 386-392.

2) Boyarsky, S., Kirshner, N. \& Labay, P. (1966) Catecholamine content of the normal dog ureter. Invest. Urol., 4, 97-102.

3) Boyarsky, S. \& Labay, P. (1967) Stimulation of ureteral peristalsis through the renal nerves. Invest. Urol., 5, 200-202.

4) Boyarsky, S., Labay, P. \& Glenn, J.F. (1968) More evidence for ureteral nerve function and its clinical implications. $J$. Urol., 99, 533-538.

5) Boyarsky, S., Labay, P., Kirshner, N. \& Gerber, C. (1967) Does the ureter have nervous control? J. Urol., 97, 627-632.

6) Butcher, H.R., Sleator, W. \& Schmandt, W.P. (1957) A study of the peristaltic conduction mechanism in the canine ureter. $J$. Urol., 78, 221-231.

7) Chen, P.S., Emmel, V.M., Benjamin, J.A. \& Distefano, V. (1957) Studies on the isolated dog ureter. The Pharmacological action of histamine, levarterenal and antihistaminies. Arch. int. Pharmacodyn., 110, 131-141.

8) Deane, R.F. (1967) Functional studies of the ureter: its behaviour in the domestic pig (Sus scrofa domestrica) as recorded by the technique of Trendelenburg. Brit. J. Urol., 39, 31-37.

9) Deane, R.F. \& Garry, R.C. (1966) The behavior of the ureter of the pig recording by Trendedlenburg technique. J. Physiol., 183, 36P-37P.

10) Dogiel, A. (1878) Zur Kenntniss der Nerven der Ureteren. Arch. mikr. Anat., 15, 64-66.

11) Engelmann, T.W. (1869) Zur Physiologie des Ureter. Arch. ges. Physiol., 2, 243293.

12) Gruber, C.M. (1928) The peristaltic and antiperistaltic movements in exeised ureters as affected by drugs. $J$. Urol., 20, 27-59.

13) Hasegawa, K. (1961) Electromyographic study on the dog's ureter under dissection of the nerves innervating kidney and ureter. Tohoku Igaku Zasshi. (Jap.), 64, 365376.

14) Hryntschak, T. (1925) Beiträge zur Physiologie des Ureters. I. Zur Harnleiterautomatie. Pflügers Arch f.d. ges. Physiol., 209, 542-561.

15) Kao, C.Y. (1966) Tetrodotoxin, saxitoxin and their significance in the study of 
excitable phenomena. Pharmacol. Rev., 18, 997-1049.

16) Kaplan, N., Elkin, M. \& Sharkey, J. (1968) Ureteral peristalsis and the autonomic nervous system. Invest. Urol., 5, 468-482.

17) Kiil, F. (1957) The Function of the Ureter and Renal Pelvis; Saunders Co., Philadelphia and London.

18) Kiil, F. \& Kjekshus, J. (1966) The physiology of the ureter and renal polvis. Proc. 3rd int. Congr. Nephrol., Washington, 2, 321-335.

19) Kuwabara, M. \& Rikimaru, A. (1969) Studies on the regulatory mechanism of peristalsis in the isolated dog ureter. Jap. J. Smooth Muscle Res. (Jap.), 5, 244-255.

20) Lapides, J. (1948) The physiology of the intact human ureter. J. Urol, 59, 501537.

21) Lucas, D.R. (1908) Physiological and pharmacological studies of the ureter (III). Amer. J. Physiol., 22, 245-278.

22) Macht, D.I. (1916) On the pharmacology of the ureter. II. Action of drugs affecting the sacral autonimics. J. Pharmacol. exp. Therap., 8, 261-271.

23) Malin, J.M., Jr., Boyarsky, S., Labay, P. \& Gerber, C. (1968) In vitro isometric studies of ureteral smooth muscle. J. Urol., 99, 396-398.

24) Notley, R.G. (1968) Electron microscopy of the upper ureter and the palvi-ureteric junction. Brit. J. Urol., 40, 37-52.

25) O'Conor, V.J. (1939) Prostigmin as an aid in the expulsion of ureteral calculi. Brit. J. Urol., 11, 325-331.

26) Roth, G.B. (1917) On the movements of the excised ureter of the dog. Amer. J. Physiol., 44, 275-289.

27) Satani, Y. (1919) Experimental studies of the ureter. Amer. J. Physiol., 49, 474495.

28) Shiratori, T., Suetake, Y., Teshima, H., Katayose, K., Naito, T., Enokido, K., Takakura, K., Chiba, K., Naganuma, H. \& Kinoshita, H. (1957) Electromyographic studies on the ureter of dogs and human beings. Tohoku Igaku Zasshi (Jap.), 55, 382-390.

29) Sleator, W., Jr. \& Butcher, H.R. (1955) Action potentials and pressure changes in ureteral peristaltic waves. Amer. J. Physiol., 180, 261-276.

30) Torbey, K. \& Leadbetter, W.F. (1963) Innervation of the bladder and lower ureter: Studies on pelvic nerve section and stimulation in the dog. J. Urol., 90, 395-404.

31) Tsuchida, S. (1969) Computer analyses of urometrographic and electroureterographic data on the ureteral function at various urine flow rates. Tohoku J. exp. Med., 97, $297-310$.

32) Tsuchida, S. (1970) Some factors controlling ureteral peristalsis. Tohoku J. exp. Med., 101, 55-66.

33) Tsuchida, S. (1971) A technique for monitoring ureteral peristalsis to remove the effect of changing urine flow. Toholu $J$. exp. Med., 104, 251-262.

34) Tsuchida, S. \& Kimura, Y. (1964) Electromyography of the ureter through cystoscope. Tohoku K. exp. Med., 83, 1-10.

35) Tsuchida, S., Someno, T. \& Nakano, N. (1968) The ureteral function in neurogenic bladder patients. Tohoku $J$. exp. Med., 95, 221-234. 